\title{
H-Abstraction by OH from Large Branched Alkanes: Overall Rate Measurements and Site-specific Tertiary Rate Calculations
}

Dapeng Liu ${ }^{a}$, Fethi Khaled ${ }^{\mathrm{a}}$, B.R. Giri ${ }^{\mathrm{a}}$, Emmanuel Assaf $^{\mathrm{b}}$, Christa Fittschen ${ }^{\mathrm{b}}$, Aamir Farooq, ${ }^{\mathrm{a},{ }^{*}}$ ${ }^{\mathrm{a} C l e a n}$ Combustion Research Center, King Abdullah University of Science and Technology, Thuwal, Kingdom of Saudi Arabia 23955, Saudi Arabia

${ }^{\mathrm{b}}$ Université Lille, CNRS, UMR 8522 - PC2A - Physicochimie des Processus de Combustion et de l'Atmosphère, F-59000 Lille, France

*Corresponding Author - Email: Aamir.Farooq@,kaust.edu.sa 


\begin{abstract}
Reaction rate coefficients for the reaction of hydroxyl $(\mathrm{OH})$ radicals with nine large branched alkanes (i.e., 2-methyl-3-ethyl-pentane, 2,3-dimethyl-pentane, 2,2,3-trimethyl-butane, 2,2,3trimethyl-pentane, 2,3,4-trimethyl-pentane, 3-ethyl-pentane, 2,2,3,4-tetramethyl-pentane, 2,2dimethyl-3-ethyl-pentane and 2,4-dimethyl-3-ethyl-penatane) are measured at high temperatures $(900-1300 \mathrm{~K})$ using a shock tube and narrow line-width $\mathrm{OH}$ absorption diagnostic in the UV region. In addition, room-temperature measurements of six out of these nine rate coefficients are performed in a photolysis cell using high repetition laser-induced fluorescence (LIF) of $\mathrm{OH}$ radicals. Our experimental results are combined with previous literature measurements to obtain three-parameter Arrhenius expressions valid over a wide temperature range $(300-1300 \mathrm{~K})$.
\end{abstract}

The rate coefficients are analyzed using the next-nearest-neighbor (N-N-N) methodology to derive nine tertiary $\left(\mathrm{T}_{003}, \mathrm{~T}_{012}, \mathrm{~T}_{013}, \mathrm{~T}_{022}, \mathrm{~T}_{023}, \mathrm{~T}_{111}, \mathrm{~T}_{112}, \mathrm{~T}_{113}\right.$, and $\left.\mathrm{T}_{122}\right)$ site-specific rate coefficients for the abstraction of $\mathrm{H}$ atoms by $\mathrm{OH}$ radicals from branched alkanes. Derived Arrhenius expressions, valid over $950-1300 \mathrm{~K}$, are given as (the subscripts denote the number of carbon atoms connected to the next-nearest-neighbor carbon):

$$
\begin{aligned}
& T_{003}=1.80 \times 10^{-10} \exp (-2971 \mathrm{~K} / \mathrm{T}) \mathrm{cm}^{3} \text { molecule } \mathrm{e}^{-1} \mathrm{~s}^{-1} \\
& T_{012}=9.36 \times 10^{-11} \exp (-3024 \mathrm{~K} / T) \mathrm{cm}^{3} \text { molecule } \mathrm{s}^{-1} \\
& T_{013}=4.40 \times 10^{-10} \exp (-4162 \mathrm{~K} / \mathrm{T}) \mathrm{cm}^{3} \text { molecule }{ }^{-1} \mathrm{~s}^{-1} \\
& T_{022}=1.47 \times 10^{-10} \exp (-3587 \mathrm{~K} / \mathrm{T}) \mathrm{cm}^{3} \text { molecule } \mathrm{e}^{-1} \mathrm{~s}^{-1} \\
& T_{023}=6.06 \times 10^{-11} \exp (-3010 \mathrm{~K} / \mathrm{T}) \mathrm{cm}^{3} \text { molecule } \mathrm{e}^{-1} \mathrm{~s}^{-1} \\
& T_{111}=3.98 \times 10^{-11} \exp (-1617 \mathrm{~K} / \mathrm{T}) \mathrm{cm}^{3} \text { molecule }{ }^{-1} \mathrm{~s}^{-1} \\
& T_{112}=9.08 \times 10^{-12} \exp (-3661 \mathrm{~K} / \mathrm{T}) \mathrm{cm}^{3} \text { molecule } \mathrm{e}^{-1} \mathrm{~s}^{-1} \\
& T_{113}=6.74 \times 10^{-9} \exp (-7547 \mathrm{~K} / \mathrm{T}) \mathrm{cm}^{3} \mathrm{molecule}^{-1} \mathrm{~s}^{-1} \\
& T_{122}=3.47 \times 10^{-11} \exp (-1802 \mathrm{~K} / \mathrm{T}) \mathrm{cm}^{3} \text { molecule }{ }^{-1} \mathrm{~s}^{-1}
\end{aligned}
$$




\section{Introduction}

Alkanes are essential components of gasoline, diesel, and aviation fuels ${ }^{1}$. It is wellrecognized that hydroxyl $(\mathrm{OH})$ radicals are crucial species in alkane oxidation processes under combustion as well as atmospheric conditions ${ }^{2-4}$. Reaction rates of $\mathrm{OH}$ with small alkanes ( $\leq$ C6) have been studied extensively in the literature ${ }^{5-9}$. However, there is considerable lack of direct measurements of $\mathrm{OH}$ reaction with large $(\geq \mathrm{C} 7)$ normal and branched alkanes, particularly, at high temperatures relevant to combustion.

By using the laser photolysis/laser-induced fluorescence (LIF) technique, Tully and coworkers $5,7,10-12$ measured the rate constants of various alkanes with $\mathrm{OH}$ for temperatures below $903 \mathrm{~K}$ and characterized the site-specific (primary, secondary, and tertiary) $\mathrm{H}$ abstractions. Cohen and co-workers ${ }^{4,9,13}$ performed single-point measurements of various hydrocarbon $+\mathrm{OH}$ reactions near $1200 \mathrm{~K}$ in shock tube experiments. To accurately describe the non-Arrhenius behavior ${ }^{14}$ of these data, Sivaramakrishnan et al. ${ }^{15}$ studied the reaction rates of selected branched and normal alkanes with $\mathrm{OH}$ over $797-1259 \mathrm{~K}$. Pang et al. ${ }^{16}$ measured the rate constants for three normal alkanes (n-pentane, n-heptane, and n-nonane) with $\mathrm{OH}$ over $869-1364 \mathrm{~K}$. Badra et al. ${ }^{17-18}$ measured the rate constants of $\mathrm{OH}$ with several normal and branched alkanes (2,2-dimethyl-pentane, 2,4-dimethyl-pentane, 2,2,4-trimethylpentane, 2,3-dimethyl-pentane, 2,2-dimethyl-butane, 4-methyl-heptane, 3-methyl-pentane, 2methyl-pentane, 2-methyl-heptane and n-hexane) over 840 - $1470 \mathrm{~K}$.

Group-additivity transition-state-theory (TST) ${ }^{14,19}$ and structure-activity relationship (SAR) ${ }^{20-21}$ methods have been developed to predict rate coefficients for the reaction of $\mathrm{OH}$ with hydrocarbons and oxygenates. Cohen extrapolated the single-point temperature experimental data to a broader temperature range for several alkanes utilizing the TST method and introduced the next-nearest-neighbor $(\mathrm{N}-\mathrm{N}-\mathrm{N})$ methodology ${ }^{14,22}$. According to the N-N-N designation, $\mathrm{C}-\mathrm{H}$ bonds of alkanes may be divided into three groups, i.e., primary (P), 
secondary (S), and tertiary (T) C-H bonds. Furthermore, depending on the number of carbon atoms connected to the nearest carbon atom, the $\mathrm{C}-\mathrm{H}$ bonds may be divided into four primaries, ten secondaries, and twenty tertiaries. Sivaramakrishnan et al. ${ }^{23}$ extended the NN-N method by determining several site-specific H-abstraction rate coefficients which were used to predict reaction rates for alkanes up to n-cetane. However, extension to larger branched alkanes was not feasible due to the absence of sufficient secondary and tertiary sitespecific H-absorption rates. Badra et al. ${ }^{17-18}$ determined the remaining secondary sitespecific rates and two tertiary site-specific rates.

Experimental measurements for the remaining sixteen tertiary site-specific rates are missing, which are indispensable for predicting the rate coefficients of all branched alkanes with $\mathrm{OH}$ while employing the N-N-N methodology. In the current work, we have chosen nine branched alkanes carefully to extract nine tertiary site-specific H-abstraction rates. We measured the overall rate constants of reactions R1 - R9 behind reflected shock waves over a temperature range of 850 to $1428 \mathrm{~K}$ and pressure near $1.5 \mathrm{~atm}$. This work reports, to our knowledge, the first direct experimental rate measurements of these reactions.

$$
\begin{gathered}
\text { 2-methyl-3-ethyl-pentane }+\mathrm{OH} \rightarrow \text { Products } \\
\text { 2,3-dimethyl-pentane }+\mathrm{OH} \rightarrow \text { Products } \\
\text { 2,2,3-trimethyl-butane }+\mathrm{OH} \rightarrow \text { Products } \\
\text { 2,2,3-trimethyl-pentane }+\mathrm{OH} \rightarrow \text { Products } \\
\text { 2,3,4-trimethyl-pentane }+\mathrm{OH} \rightarrow \text { Products } \\
\text { 3-ethyl-pentane }+\mathrm{OH} \rightarrow \text { Products } \\
\text { 2,2,3,4-tetramethyl-pentane }+\mathrm{OH} \rightarrow \text { Products } \\
\text { 2,2-dimethyl-3-ethyl-pentane }+\mathrm{OH} \rightarrow \text { Products } \\
\text { 2,4-dimethyl-3-ethyl-penatane }+\mathrm{OH} \rightarrow \text { Products }
\end{gathered}
$$

Room-temperature rate constant data are available in literature for 2,3-dimethyl-pentane ${ }^{24}$, 2,2,3-trimethyl-butane ${ }^{25-27}$ and 2,3,4-trimethyl-pentane ${ }^{28-29}$. Remaining room-temperature rate constants were measured in this work using a flow reactor. High-temperature $(850-1428$ 
K) rate constant data are combined with the room-temperature data to propose modified Arrhenius expressions, valid over $294-1428 \mathrm{~K}$, for the reaction of $\mathrm{OH}$ with these nine alkanes.

The selected alkanes contain $\mathrm{T}_{003}, \mathrm{~T}_{012}, \mathrm{~T}_{013}, \mathrm{~T}_{022}, \mathrm{~T}_{023}, \mathrm{~T}_{111}, \mathrm{~T}_{112}, \mathrm{~T}_{113}$ and $\mathrm{T}_{122}$ tertiary $\mathrm{C}$ $\mathrm{H}$ sites. High-temperature rate data of reactions R1-R9 are combined with previous studies on alkanes $+\mathrm{OH}$ to determine nine new tertiary site-specific rate constants for $\mathrm{H}$-abstraction by $\mathrm{OH}$, as well as to optimize literature reported rate coefficients of relevant primary and secondary C-H sites.

\section{Experimental methods}

\subsection{High-temperature experiments of Alkanes $+\mathrm{OH} \rightarrow$ Products}

High-temperature experiments of the reaction of nine large alkanes with $\mathrm{OH}$ were carried out in the low-pressure shock tube (LPST) facility at King Abdullah University of Science and Technology (KAUST). A detailed description of the shock tube and $\mathrm{OH}$ absorption diagnostic have been presented elsewhere ${ }^{30-31}$; only a brief description is given here. The length of the driver section of the shock tube is adjustable to a maximum $9 \mathrm{~m}$ while driven section has a fixed length of $9 \mathrm{~m}$. The inner diameter of both parts is $14.2 \mathrm{~cm}$. Incident shock velocity was measured using five equally spaced pressure transducers placed along the last $1.3 \mathrm{~m}$ of the driven section of the shock tube. Standard shock-jump relations were used to calculate pressure and temperature behind reflected shock waves with measured incident shock velocity and thermodynamic parameters of the gas mixture as inputs. Uncertainty in the incident shock speed measurement is about $\pm 0.2 \%$ which gives rise to pressure and temperature uncertainty of about $\pm 1 \%$ and $\pm 0.7 \%$, respectively. Gaseous mixtures of alkane, tert-butyl-hydroperoxide (TBHP) and bath gas (argon) were prepared manometrically in a 24litre mixing vessel which is magnetically stirred. Mixtures are generally left to mix for about 
2 hours before use in the shock tube. Between every run, the shock tube is pumped down to $10^{-5}$ Torr using a turbomolecular vacuum pump.

Tert-butyl-hydroperoxide (TBHP) was used to produce clean $\mathrm{OH}$ rapidly, and has been validated previously for high-temperature studies ${ }^{32-34}$. All nine alkanes (2,2,3-trimethylbutane, 2,3-dimethyl-pentane, 2,2,3-trimethyl-pentane, 2,3,4-trimethyl-pentane, 2,2,3,4tetramethyl-pentane, 3-ethyl-pentane, 2-methyl-3-ethyl-pentane, 2,2-dimethyl-3-ethyl-pentane and 2,4-dimethyl-3-ethyl-penatane) had purity of $\geq 99 \%$ and were obtained from ChemSampCo, while 30\% TBHP aqueous solution was purchased from Sigma Aldrich.

A ring-dye $\mathrm{cw}$ laser is used to produce red light at $614 \mathrm{~nm}$. Frequency doubling of this red light generates the ultraviolet (UV) light which is tuned to the center of the $R_{1}(5)$ line, near $306.69 \mathrm{~nm}$, of the $\mathrm{OH}$ electronic spectrum in the $\mathrm{A}^{2} \Sigma^{+} \leftarrow \mathrm{X}^{2} \Pi$ transition band. Intensity fluctuation of the laser is suppressed by using common-mode-rejection (CMR) scheme ${ }^{35-36}$. The Beer-Lambert Law is used to calculate the $\mathrm{OH}$ mole fraction, $I / I_{O}=\exp \left(-X_{O H} k_{O H} P L\right)$, where $I_{O}$ and $I$ are the measured incident and transmitted laser intensities, $X_{O H}$ is mole fraction of $\mathrm{OH}, k_{O H}$ is the absorption coefficient of $\mathrm{OH}, P$ is the pressure and $L$ is the path length. Uncertainty in $\mathrm{X}_{\mathrm{OH}}$ measurement is about $\pm 3 \%$ which mainly comes from the reflected-shock temperature uncertainty and absorption coefficient uncertainty.

Under pseudo-first-order conditions ([alkane] $>[\mathrm{OH}]$ ), various reflected-shock measurements were performed for each alkane with different initial alkane/TBHP concentration ratio. Initial TBHP mole fraction in the gaseous mixtures ranged from 20-30 ppm while initial alkane mole fraction ranged from 200 to $305 \mathrm{ppm}$. Detailed kinetic mechanisms were not available for any of the nine branched alkanes studied here. We used the kinetic mechanism of 2-methyl-heptane by Sarathy et al. ${ }^{37}$ as a base mechanism. A submechanism for TBHP decomposition was taken from Pang et al. ${ }^{16}$ and added to the base 
mechanism. For each alkane, a sub-mechanism was prepared which contained the alkane + $\mathrm{OH}$ abstraction channels. These sub-mechanisms were also added to the base mechanism. Constant UV (internal energy and volume) simulations were performed using the CHEKMKIN-PRO commercial package to obtain simulated $\mathrm{OH}$ profiles. The target alkane + $\mathrm{OH}$ rate constant was varied in the assembled model to achieve best fit of the simulated $\mathrm{OH}$ time-history profile with the measured $\mathrm{OH}$ profile.

\subsection{Low-temperature experiments of Alkanes $+\mathrm{OH} \rightarrow$ Products}

Low-temperature experiments were conducted at the Universite de Lille. Hydroxyl radical decays were measured by a high-repetition rate laser-induced fluorescence (LIF) diagnostic coupled to a laser photolysis flow reactor. Details of the experimental setup have been described earlier ${ }^{38-40}$ and only a brief overview is given here. The photolysis cell has three axes and is made of stainless steel, internally coated with Teflon. Hydroxyl radicals were generated by $248 \mathrm{~nm}$ photolysis of hydrogen peroxide $\left(\mathrm{H}_{2} \mathrm{O}_{2}\right)$ leading to the formation of two $\mathrm{OH}$ radicals ${ }^{41}$. Photolysis is achieved along the longest axis with an excimer laser (Lambda Physik LPX 202i) operating at a repetition rate of $1 \mathrm{~Hz}$. The excimer laser beam entering the cell through a quartz window has approximate dimensions of $1.5 \times 2.5 \mathrm{~cm}$. The photolysis energy for the current experiments was about $50 \mathrm{~mJ} \mathrm{~cm}$.

Hydroxyl radicals were excited to the (1-0) vibrational band of the A-X electronic transition at $282 \mathrm{~nm}$ using a frequency doubled output of a dye laser (Sirah), pumped by a frequency double YAG laser (Spectra Physics). The red shifted fluorescence was detected by a photomultiplier (Hamatsu R212) at around $308 \mathrm{~nm}$ through an interference filter $(308 \pm 10$ $\mathrm{nm})$. The excitation laser was run at $10 \mathrm{kHz}$, therefore, $\mathrm{OH}$ profiles were obtained after each photolysis pulse with a time resolution of $100 \mu \mathrm{s}$. A typical experiment consisted of 5000 data points (i.e., $0.5 \mathrm{~s}$ ) before each photolysis pulse to measure background signal followed by 
5000 data points after the photolysis pulse. Each data point is summed over typically $20-50$ photolysis laser pulses.

Reactant mixtures of alkanes were prepared manometrically as diluted mixtures in helium in a $10 \mathrm{~L}$ glass balloon. Mixtures were introduced into the photolysis cell through calibrated flowmeters (Tylan and Brunkhorst). A small flow of the alkane mixture (1 - $10 \mathrm{ccm}$ STP) was mixed with the main helium flow (200 ccm STP), and absolute concentrations present in the photolysis cell were calculated considering an ideal gas mixture. Alkane concentrations in the photolysis cell were adjusted to obtain $\mathrm{OH}$ decays on the order of $1000-3000 \mathrm{~s}^{-1}$, a range well adapted for the time resolution of the $\mathrm{OH}$ detection system. Hydrogen peroxide $\left(\mathrm{H}_{2} \mathrm{O}_{2}\right)$ was generated by gently heating to $40^{\circ} \mathrm{C}$ a mixture of $\mathrm{H}_{2} \mathrm{O}_{2}$-urea adduct (Sigma Aldrich) and $\mathrm{SiO}_{2}$ (Sigma Aldrich). Gaseous, water-free $\mathrm{H}_{2} \mathrm{O}_{2}$ was generated through decomposition of $\mathrm{H}_{2} \mathrm{O}_{2}$-urea and stable flows were generated by flowing helium over the mixture. Typical $\mathrm{H}_{2} \mathrm{O}_{2}$ concentrations were $\sim 2 \times 10^{14} \mathrm{~cm}^{-3}$. Total pressure in the cell was around 50 Torr and was measured by a 100 Torr Baratron.

\section{Results and Discussion}

\subsection{High-temperature rate constants of Alkanes $+\mathrm{OH} \rightarrow$ Products}

Gas mixtures of various alkane/TBHP ratios satisfying pseudo-first-order conditions were used for each alkane. For the measurement of 2-methyl-3-ethyl-pentane $+\mathrm{OH}$ reaction, two gas mixtures were used to verify that the influence of secondary reactions is negligible; a first mixture of 200 ppm 2-methyl-3-ethyl-pentane, 20 ppm TBHP (60 ppm of water) and balance Ar, and a second mixture of 304 ppm 2-methyl-3-ethyl-pentane, 25 ppm TBHP (70 ppm of water) and balance Ar. The gaseous mixtures were shock-heated to temperatures of $994-$ $1357 \mathrm{~K}$ and pressures near $1.5 \mathrm{~atm}$. Using the assembled mechanism described earlier, hydroxyl sensitivity analysis was performed using CHEMKIN-PRO to determine the relevant 
reactions at our conditions. The $\mathrm{OH}$ sensitivity coefficient is defined as $S_{O H}=\left(\partial X_{O H} / \partial k_{i}\right) \times$ $\left(k_{i} / X_{O H}\right)$, where $X_{O H}$ is mole fraction of $\mathrm{OH}$ and $k_{i}$ is the rate coefficient of the $\mathrm{i}^{\text {th }}$ reaction. A representative $\mathrm{OH}$ sensitivity is plotted in Fig. 1 at $994 \mathrm{~K}$ and shows that the $\mathrm{OH}$ profile is mainly sensitive to the 2-methyl-3-ethyl-pentane $+\mathrm{OH}$ reaction. Similar results of sensitivity analyses were obtained for the other alkanes studied in this work. Figure 1 shows minor interferences from secondary reactions involving $\mathrm{CH}_{3}$ and acetone. The rates of these secondary reactions were updated in the assembled mechanism utilizing the values suggested by Badra et al. ${ }^{31}$.

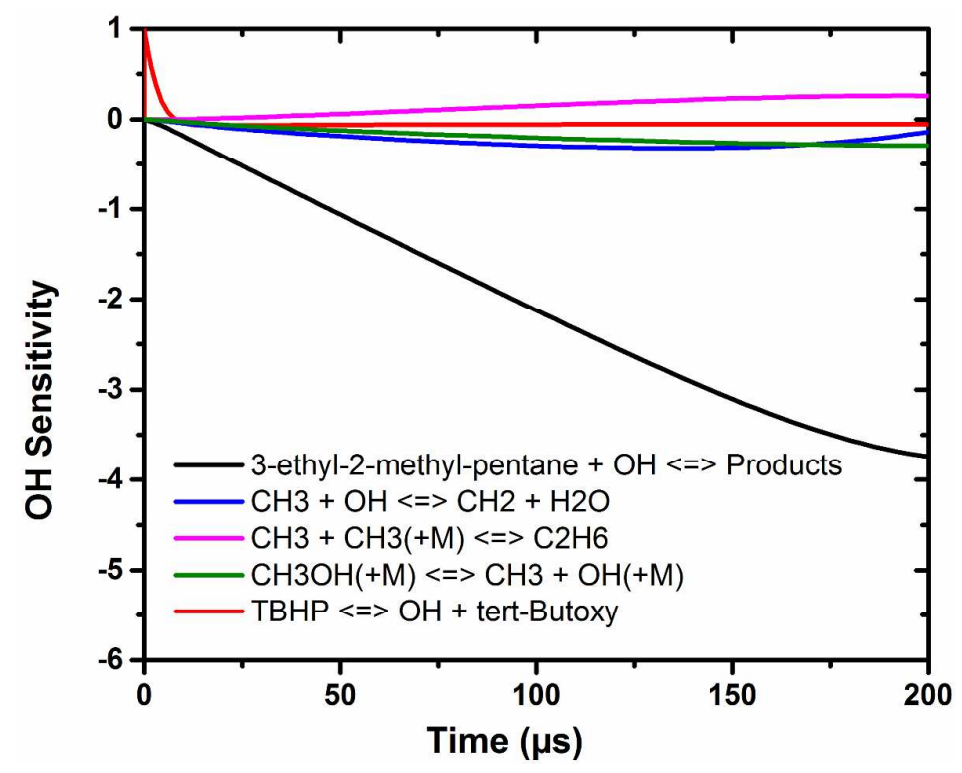

Fig. 1. Hydroxyl sensitivity for the rate constants measurement of 2-methyl-3-ethyl-pentane $+\mathrm{OH}$ at $994 \mathrm{~K}$ and $1.34 \mathrm{~atm}$. Mixture: 200 ppm 2-methyl-3-ethyl-pentane, 20 ppm TBHP (47 ppm $\mathrm{H}_{2} \mathrm{O}$ ), balance Ar.

There are five pathways for the reaction of 2-methyl-3-ethyl-pentane with $\mathrm{OH}$ radicals:

$$
\begin{aligned}
& \mathrm{C}_{8} \mathrm{H}_{18}-2-3+\mathrm{OH} \rightarrow \mathrm{C}_{8} \mathrm{H}_{18}-2-3 \mathrm{a}+\mathrm{H}_{2} \mathrm{O} \\
& \mathrm{C}_{8} \mathrm{H}_{18}-2-3+\mathrm{OH} \rightarrow \mathrm{C}_{8} \mathrm{H}_{18}-2-3 \mathrm{~b}+\mathrm{H}_{2} \mathrm{O} \\
& \mathrm{C}_{8} \mathrm{H}_{18}-2-3+\mathrm{OH} \rightarrow \mathrm{C}_{8} \mathrm{H}_{18}-2-3 \mathrm{c}+\mathrm{H}_{2} \mathrm{O} \\
& \mathrm{C}_{8} \mathrm{H}_{18}-2-3+\mathrm{OH} \rightarrow \mathrm{C}_{8} \mathrm{H}_{18}-2-3 \mathrm{~d}+\mathrm{H}_{2} \mathrm{O}
\end{aligned}
$$




$$
\mathrm{C}_{8} \mathrm{H}_{18}-2-3+\mathrm{OH} \rightarrow \mathrm{C}_{8} \mathrm{H}_{18}-2-3 \mathrm{e}+\mathrm{H}_{2} \mathrm{O}
$$

A sub-mechanism containing all reaction pathways is set up with reference rate constant data taken from the kinetic mechanism of 2-methyl-alkanes by Sarathy et al. ${ }^{37}$ (details of submechanism for the nine alkanes is given in Table S4 of the Supplementary Material). Temperature-dependent branching ratios for different abstraction channels may be calculated from the base mechanism. The branching ratios of these channels do not influence the $\mathrm{OH}$ concentration profile as mentioned by Badra et al. ${ }^{18}$ and Wang et al. ${ }^{42}$, and these are kept constant for a certain temperature during the mechanism fitting process. A representative measured $\mathrm{OH}$ time-history profile $(1145 \mathrm{~K}$ and $1.34 \mathrm{~atm})$, best-fit simulated $\mathrm{OH}$ profile $\left(k_{\text {total }}=k_{l a}+k_{l b}+k_{l c}+k_{l d}+k_{l e}\right)$, and perturbations of the best fit profile by $\pm 50 \%$ are presented in Fig. 2. The best-fit simulation profile gives a rate constant value of $3.79 \times 10^{-11}$ $\mathrm{cm}^{3}$ molecule $\mathrm{s}^{-1}$. Measured rate constant values are listed in Table 1 along with corresponding temperatures and pressures.

A detailed uncertainty analysis was performed for each of the data points presented here. Uncertainty for the measured rate constants mainly comes from the temperature $( \pm 0.7 \%), \mathrm{OH}$ mole fraction $( \pm 3 \%)$, gas composition $( \pm 5 \%)$, OH laser frequency $\left( \pm 0.002 \mathrm{~cm}^{-1}\right)$, fixing zero time ( \pm 0.5 us), uncertainty of fitting $\mathrm{OH}$ time-history profile $( \pm 5 \%)$, and uncertainty in the rate constants of relevant secondary reactions. The contribution of each of these error sources on the determination of the overall rate constant is calculated separately. The total uncertainty for $\mathrm{R} 1$ at $994 \mathrm{~K}$ is calculated to be $\pm 20 \%$ by the root-sum-squared method. Uncertainties in the rate measurement of the other eight alkanes at around $1000 \mathrm{~K}$ are also approximately \pm $20 \%$. 


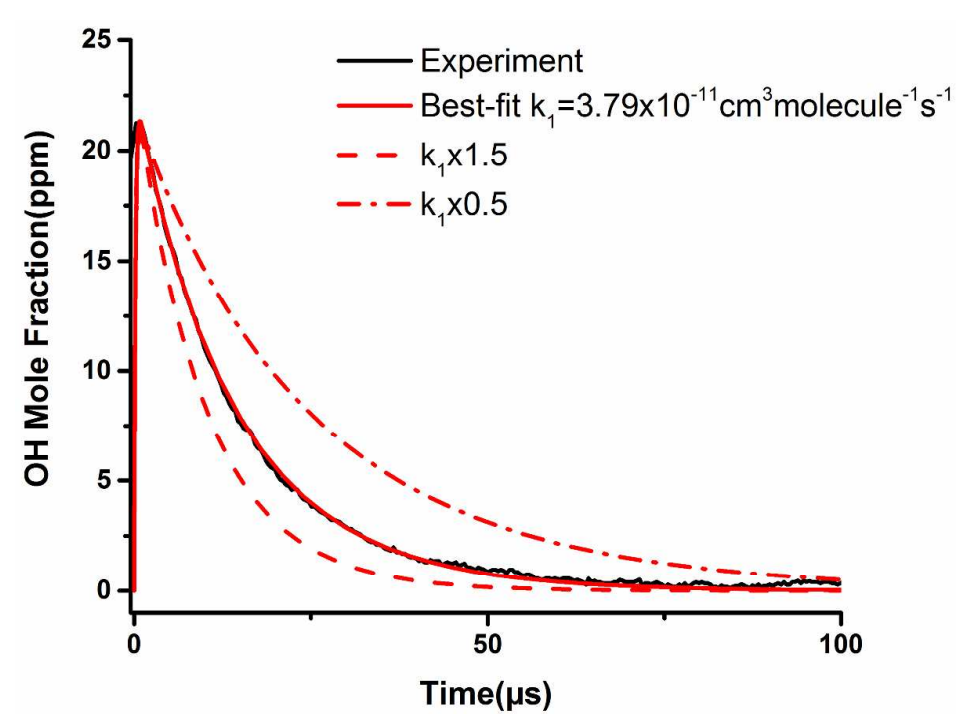

Fig. 2. Representative $\mathrm{OH}$ time-history profile for 2-methyl-3-ethyl-pentane $+\mathrm{OH}$ reaction rate measurement at $1145 \mathrm{~K}$ and $1.34 \mathrm{~atm}$. The best-fit simulated profile and perturbation of best-fit rate by $\pm 50 \%$ are also plotted.

Figure 3 shows Arrhenius plot of the experimentally measured rate constants of 2methyl-3-ethyl-pentane $+\mathrm{OH}$ reaction. Rate constant values predicted by the structureactivity relationship (SAR) method are also plotted. The SAR method captures the measured rate constants within $20 \%$. Figure 3 also shows rate constant calculated using the N-N-N methodology where the N-N-N site-specific rates are taken from Table 3. Measured values of $k_{l}$ can be described in an Arrhenius form as:

$$
k_{1}=3.07 \times 10^{-10} \exp (-2317 \mathrm{~K} / T) \mathrm{cm}^{3} \text { molecule }^{-1} \mathrm{~s}^{-1}(994-1357 \mathrm{~K})
$$




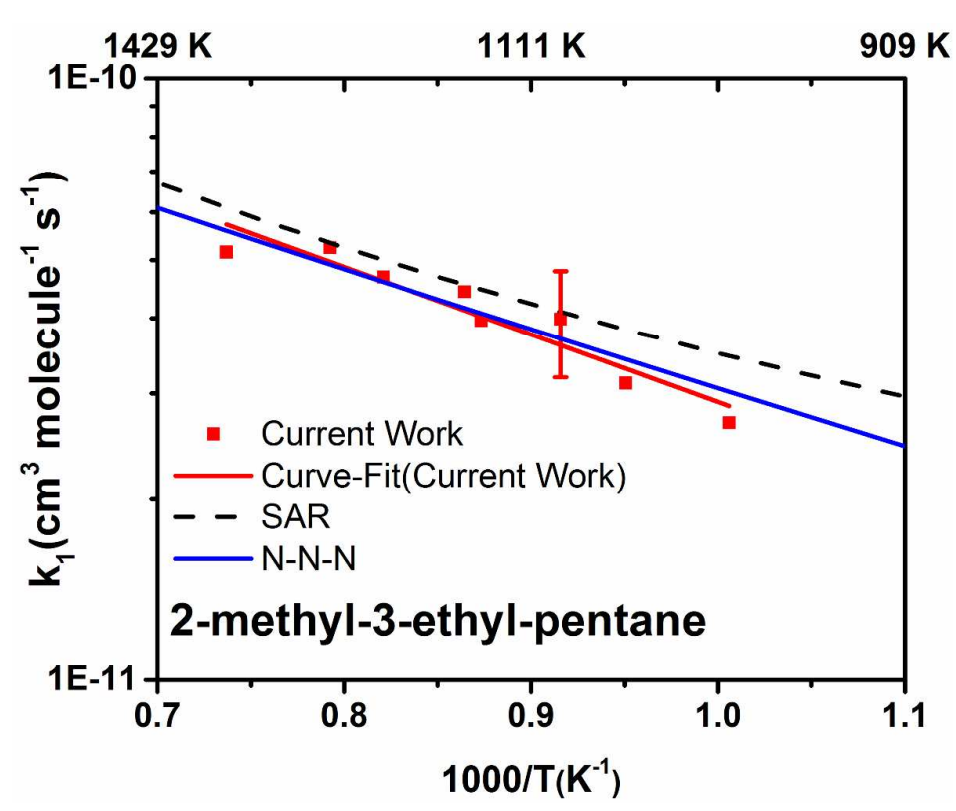

Fig. 3. Arrhenius plot of 2-methyl-3-ethyl-pentane $+\mathrm{OH} \Rightarrow$ products.

The reaction rate constants of $\mathrm{OH}$ with the remaining eight alkanes were measured in a similar manner. For each alkane, at least two different gas mixtures satisfying pseudo-firstorder condition with varying alkane/TBHP concentration ratios were used. In these alkane/TBHP/Ar mixtures, alkane mole fractions range from $200 \mathrm{ppm}$ to $300 \mathrm{ppm}$, and TBHP ranged from $15 \mathrm{ppm}$ to $25 \mathrm{ppm}$. Uncertainty estimates for $k_{2}-k_{9}$ are calculated to be less than $20 \%$ near $1000-1100 \mathrm{~K}$. Figure 4 shows Arrhenius plots of $k_{2}-k_{9}$ with experimental data, best fit to the data, and predicted values from the SAR method and N-N-N method. In general, SAR estimation does a good job of predicting the measured rate constants. The disagreement is largest for 2,2,3-trimethyl-butane and 2,2-dimethyl-3-ethyl-pentane perhaps because of double branching at the second site. We also notice that compared to the measured rate constants the SAR estimation has slightly smaller activation energy for some of the reactions. Table 1 lists Arrhenius parameters of the nine measured high-temperature rate constants, corresponding experimental conditions could be found in Table S1 and Table S2 of the Supplementary Material. 

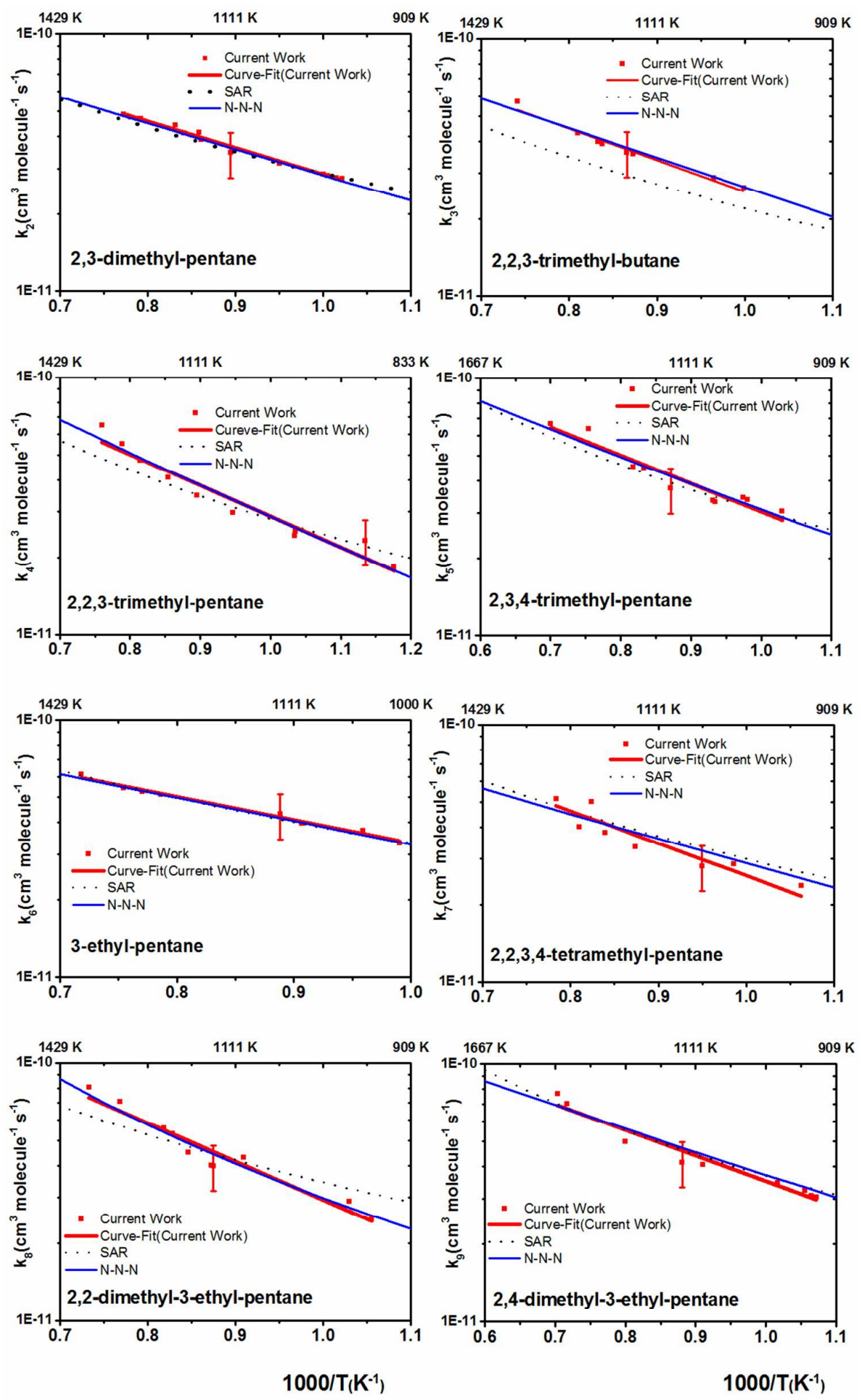

Fig. 4. Arrhenius plots of measured rate constants and SAR estimations for alkane $+\mathrm{OH} \Rightarrow$ products. 
Table 1. Arrhenius parameters obtained from the best-fit of the measured high-temperature rate constants of alkanes $+\mathrm{OH} \Rightarrow$ products, according to the expression $\mathrm{k}=\mathrm{Aexp}(-\mathrm{E} / \mathrm{T})$ $\mathrm{cm}^{3}$ molecule $\mathrm{s}^{-1}$.

\begin{tabular}{llll}
\hline Alkane & $\mathbf{A}$ & $\mathbf{E}$ & $\mathbf{T}(\mathbf{K})$ \\
\hline 2-methyl-3-ethyl-pentane $\left(k_{1}\right)$ & $3.07 \mathrm{E}-10$ & 2317 & $994-1357 \mathrm{~K}$ \\
2,3-dimethyl-pentane $\left(k_{2}\right)$ & $3.04 \mathrm{E}-10$ & 2368 & $979-1294 \mathrm{~K}$ \\
2,2,3-trimethyl-butane $\left(k_{3}\right)$ & $5.35 \mathrm{E}-10$ & 3085 & $1001-1350 \mathrm{~K}$ \\
2,2,3-trimethyl-pentane $\left(k_{4}\right)$ & $4.58 \mathrm{E}-10$ & 2764 & $850-1316 \mathrm{~K}$ \\
2,3,4-trimethyl-pentane $\left(k_{5}\right)$ & $3.74 \mathrm{E}-10$ & 2510 & $971-1428 \mathrm{~K}$ \\
3-ethyl-pentane $\left(k_{6}\right)$ & $2.63 \mathrm{E}-10$ & 2068 & $1010-1392 \mathrm{~K}$ \\
2,2,3,4-tetramethyl-pentane $\left(k_{7}\right)$ & $4.65 \mathrm{E}-10$ & 2889 & $941-1276 \mathrm{~K}$ \\
2,2-dimethyl-3-ethyl-pentane $\left(k_{8}\right)$ & $9.10 \mathrm{E}-10$ & 3432 & $948-1364 \mathrm{~K}$ \\
2,4-dimethyl-3-ethyl-pentane $\left(k_{9}\right)$ & $3.45 \mathrm{E}-10$ & 2285 & $933-1422 \mathrm{~K}$ \\
\hline
\end{tabular}

\subsection{Low-temperature rate constants of Alkane $+\mathrm{OH} \rightarrow$ Products}

The rate coefficients of the reaction of $\mathrm{OH}$ radicals with 2,3-dimethyl-pentane, 2,2,3trimethyl-butane, and 2,3,4-trimethyl-pentane have previously been measured at low temperatures. For the remaining six alkanes, low-temperature rate constants are measured in this work at room temperature $(294 \mathrm{~K})$ in a photolysis cell using high-repetition LIF diagnostic for $\mathrm{OH}$ detection. Pseudo-first-order conditions were maintained, i.e., $\mathrm{OH}$ radicals were generated in the presence of a large excess of alkane. Under these conditions, the $\mathrm{OH}$ decay rate, $k_{o b s}$, can be expressed as:

$$
\frac{d[O H]}{d t}=-k_{o b s} \times[O H]
$$

where $k_{o b s}=k_{\text {alkane }+O H} \times$ [alkane]. Figure 5 presents the pseudo-first order rate constants $\left(\mathrm{k}_{o b s}\right)$ as a function of the corresponding alkane concentration. As expected, the $\mathrm{OH}$ decay rate increase linearly with alkane concentration. The non-zero intercept (between $300-500 \mathrm{~s}^{-1}$ ) is due to the reaction of $\mathrm{OH}$ radicals with the precursor $\mathrm{H}_{2} \mathrm{O}_{2}$. Table 2 summarizes the obtained rate constants at $294 \mathrm{~K}$; detailed experimental condition are given in Table S3 of the 
Supplementary Material. The uncertainty limits in Table 2 are statistical only (95\% confidence interval). Flow meters have been calibrated before the experiments and are known to better than $\pm 1 \%$. Pressures have been measured by calibrated Baratron gauges and are estimated to be known within $\pm 1 \%$ during preparation of the mixtures as well as for the total pressure in the photolysis reactor. The temperature measurement uncertainty is $\pm 1 \mathrm{~K}$. The leak rate into the photolysis cell has been measured through pressure increase into a known volume and was $3 \mathrm{~cm}^{3} \mathrm{STP}$, to be compared to total flows of around $500 \mathrm{~cm}^{3} \mathrm{STP}$. The flow from the lead has been taken into account for the calculation of the concentration. As a result, we estimate the total uncertainty on the rate constants to be less than $5 \%$.

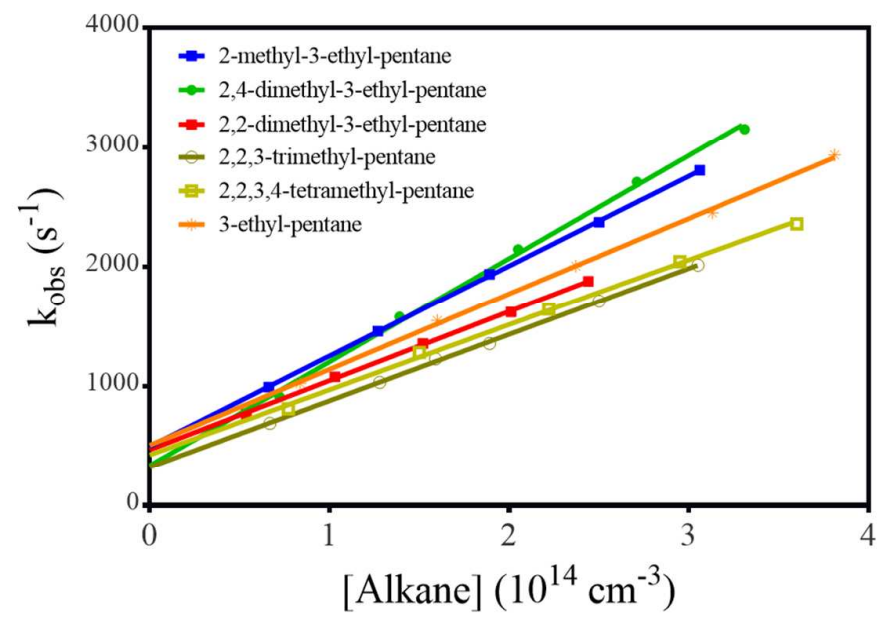

Fig. 5. Plot of $k_{o b s}$ as a function of the alkane concentration. Measurements performed at 294 $\pm 1 \mathrm{~K}$ and 50 Torr.

Table 2. Measured rate constants for alkanes $+\mathrm{OH} \Rightarrow$ products at $294 \pm 1 \mathrm{~K}$. Quoted errors are statistical only from linear regressions.

\begin{tabular}{ll}
\hline Alkane & $k\left(10^{-12} \mathrm{~cm}^{3}\right.$ molecule $\left.^{-1} \mathrm{~s}^{-1}\right)$ \\
\hline 2-methyl-3-ethyl-pentane $\left(k_{1}\right)$ & $7.55 \pm 0.05$ \\
2,2,3-trimethyl-pentane $\left(k_{4}\right)$ & $5.54 \pm 0.07$ \\
3-ethyl-pentane $\left(k_{6}\right)$ & $6.32 \pm 0.12$ \\
2,2,3,4-tetramethyl-pentane $\left(k_{7}\right)$ & $5.44 \pm 0.15$ \\
2,2-dimethyl-3-ethyl-pentane $\left(k_{8}\right)$ & $5.77 \pm 0.08$ \\
2,4-dimethyl-3-ethyl-pentane $\left(k_{9}\right)$ & $8.66 \pm 0.25$ \\
\hline
\end{tabular}




\subsection{Combined low-to-high temperature rate constants of Alkane $+\mathrm{OH} \rightarrow$ Products}

Next, we combined the room temperature and high temperature rate constant data to derive three-parameter (modified) Arrhenius expressions valid over the wide temperature interval. For the reaction of 2-methyl-3-ethyl-pentane with $\mathrm{OH}\left(k_{1}\right)$, high-temperature and low-temperature experimental rate constants are plotted in Fig. 6 together with the modified Arrhenius fit curve. The SAR prediction is also shown for comparison. The SAR prediction follows similar trend as the experimental data but seems to overestimate the measured rates across the entire temperature range. The three-parameter Arrhenius expression of $k_{l}$ is:

$$
k_{1}=7.13 \times 10^{-19} T^{2.45} \exp (639 \mathrm{~K} / T) \mathrm{cm}^{3} \text { molecule }^{-1} \mathrm{~S}^{-1}(294-1357 \mathrm{~K})
$$

Since there is only single data point at low temperatures for $k_{1}$, the overall fit might be sensitive to the low-temperature value. To estimate the uncertainty in the overall expression caused by the low-temperature point, we varied the low-temperature data within the experiment uncertainty while keeping high-temperature data unchanged. This resulted in uncertainty of $4.3 \%, 0.4 \%$, and $0.9 \%$ in parameters $\mathrm{A}, \mathrm{B}$, and $\mathrm{E}$, respectively, for $k_{1}$.

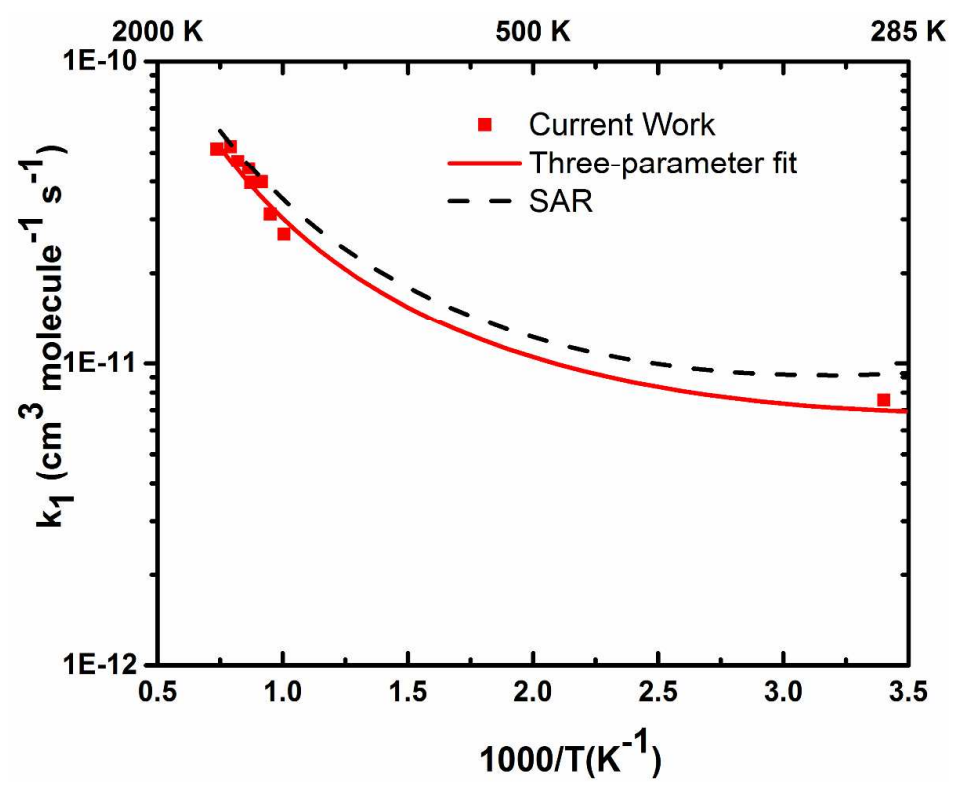

Fig. 6. Arrhenius plot of 2-methyl-3-ethyl-pentane $+\mathrm{OH} \Rightarrow$ products over 294-1357 K. 
For rate constants of 2,3-dimethyl-pentane with $\mathrm{OH}\left(k_{2}\right)$, low-temperature measurement from Wilson et al. ${ }^{24}(287-403 \mathrm{~K})$ are combined with our high-temperature data to derive modified Arrhenius expression. Figure 7 plots all experiment data, modified Arrhenius fit and SAR prediction. The SAR values agree very well with the experimental data over the entire temperature range. The three-parameter Arrhenius expression of $k_{2}$ is:

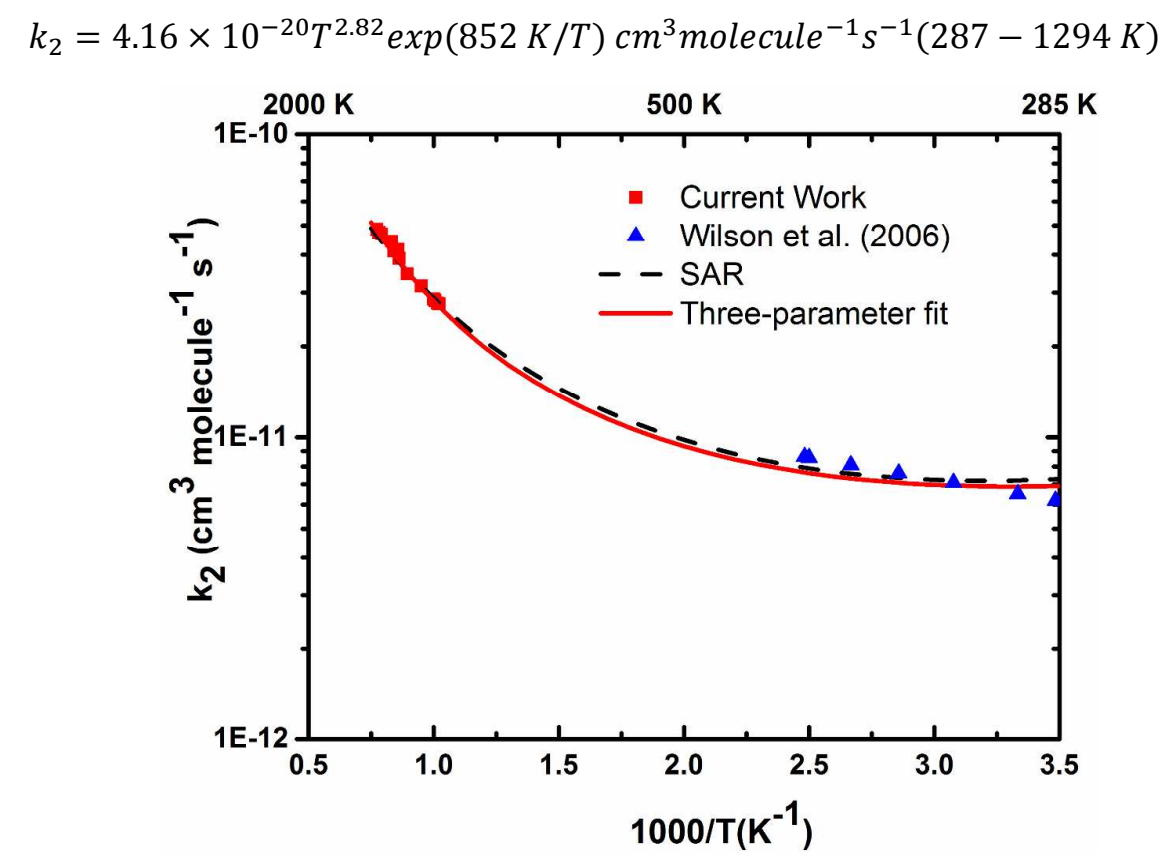

$$
k_{3}=4.26 \times 10^{-22} T^{3.45} \exp (1020 \mathrm{~K} / T) \mathrm{cm}^{3} \text { molecule }{ }^{-1} \mathrm{~S}^{-1}(296-1350 \mathrm{~K})
$$




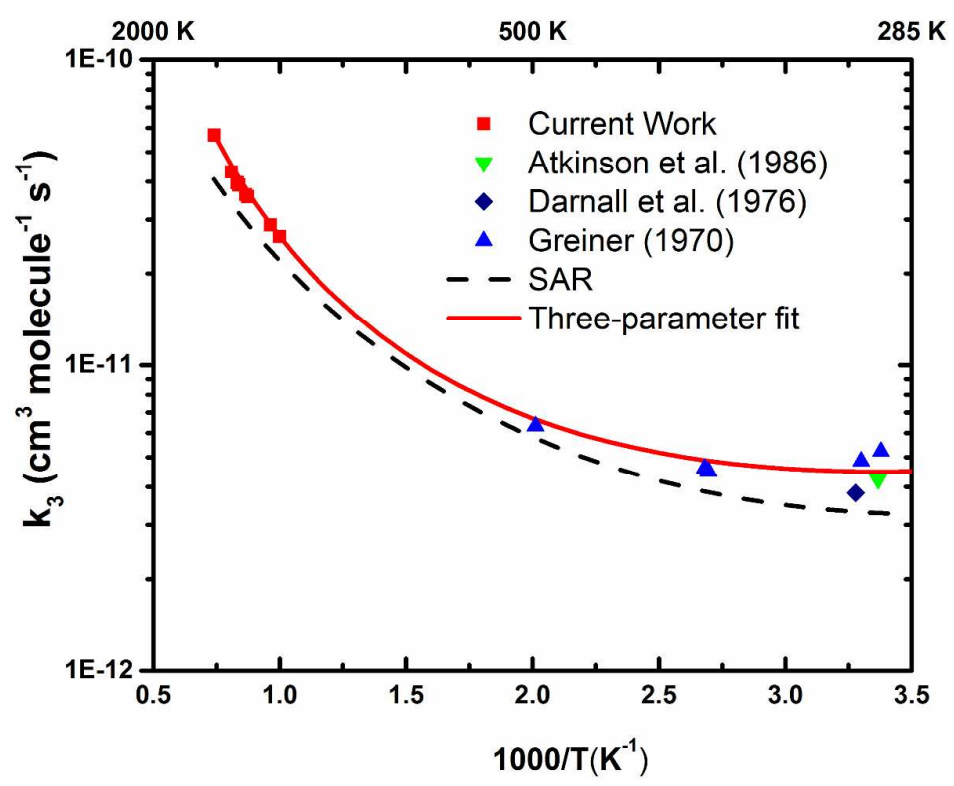

Fig. 8. Arrhenius plot of 2,2,3-trimethyl-butane $+\mathrm{OH} \Rightarrow$ products over 296-1350 K.

For the reaction of 2,3,4-trimethyl-pentane with $\mathrm{OH}\left(k_{5}\right)$, the single-point rate constant (298 K) of Aschmann et al. ${ }^{28}$ and low-temperature $(294-373 \mathrm{~K})$ values from Edmond et al. ${ }^{29}$ are used with the high-temperature data from the current work to generate the threeparameter Arrhenius expression. Edmond et al. ${ }^{29}$ measured rate constants over $244-373 \mathrm{~K}$; here, we only used their data higher than $294 \mathrm{~K}$ for consistency with other molecules. All experimental measurements, SAR estimation and curve fit are plotted in Fig. S1 of the Supplementary Material. The SAR estimation does a very good job at high temperatures but over predicts low-temperature data considerably. The three-parameter Arrhenius expression of $k_{5}$ is:

$$
k_{5}=9.81 \times 10^{-21} T^{3.04} \exp (892 \mathrm{~K} / \mathrm{T}) \mathrm{cm}^{3} \text { molecule }^{-1} \mathrm{~s}^{-1}(294-1428 \mathrm{~K})
$$

For reactions of $\mathrm{OH}$ with 2,2,3-trimethyl-pentane with $\mathrm{OH}\left(k_{4}\right)$, 3-ethyl-pentane $\left(k_{6}\right)$, 2,2,3,4-tetramethyl-pentane $\left(k_{7}\right)$, 2,2-dimethyl-pentane $\left(k_{8}\right)$, and 2,4-dimethyl-pentane $\left(k_{9}\right)$, single-temperature rate constant (294 K) from this work are used with the shock tube high- 
temperature data to generate the modified Arrhenius expressions. Plots of all experimental measurements, curve fits and SAR estimations are shown in Figs. S2-S6 of the Supplementary Material (These figures are not included in the main text to keep the paper length in check). In general, SAR reproduces the rate constants $k_{4}, k_{6}$ and $k_{9}$ reasonably well. However, for $k_{7}$ and $k_{8}$ a relatively large discrepancy is observed in the slope of the SAR estimation and the curve fit to the experimental data. We can argue that it will be highly valuable to have rate constant measurements in the intermediate temperature range to better constrain the curve fit and/or the SAR estimation. The three-parameter Arrhenius expressions are given below:

$$
\begin{gathered}
k_{4}=3.85 \times 10^{-22} T^{3.48} \exp (1022 \mathrm{~K} / T) \mathrm{cm}^{3} \text { molecule }{ }^{-1} \mathrm{~s}^{-1}(294-1316 \mathrm{~K}) \\
k_{6}=1.20 \times 10^{-17} T^{2.10} \exp (372 \mathrm{~K} / \mathrm{T}) \mathrm{cm}^{3} \text { molecule }{ }^{-1} \mathrm{~s}^{-1}(294-1392 \mathrm{~K}) \\
k_{7}=2.72 \times 10^{-21} T^{3.20} \exp (940 \mathrm{~K} / \mathrm{T}) \mathrm{cm}^{3} \text { molecule }^{-1} \mathrm{~s}^{-1}(294-1276 \mathrm{~K}) \\
k_{8}=4.78 \times 10^{-22} T^{3.46} \exp (1018 \mathrm{~K} / \mathrm{T}) \mathrm{cm}^{3} \text { molecule } \mathrm{s}^{-1}(294-1364 \mathrm{~K}) \\
k_{9}=1.82 \times 10^{-20} T^{2.96} \exp (895 \mathrm{~K} / \mathrm{T}) \mathrm{cm}^{3} \text { molecule } \mathrm{c}^{-1} \mathrm{~s}^{-1}(294-1422 \mathrm{~K})
\end{gathered}
$$

\subsection{Site-Specific tertiary abstraction rate coefficients}

Several theoretical methods have been developed to estimate the rate constants for $\mathrm{H}$ abstraction reactions of alkanes with $\mathrm{OH}$. Cohen and coworkers ${ }^{14,22}$ introduced the nextnearest-neighbor $(\mathrm{N}-\mathrm{N}-\mathrm{N})$ methodology for calculating the rate constant of $\mathrm{H}$ abstraction from various $\mathrm{C}-\mathrm{H}$ sites. All of the $\mathrm{S}$ and $\mathrm{P}$, and four out of the twenty $\mathrm{T}$ site-specific rates have been measured previously and three-parameter Arrhenius expressions for them are available in literature ${ }^{18}$. These N-N-N site-specific rates do a good job of reproducing overall abstraction rate constants for several linear and branched alkanes. However, the absence of site-specific rate coefficients for the remaining sixteen tertiary $\mathrm{C}-\mathrm{H}$ sites limits the applicability of the N-N-N method, i.e., it is not feasible to apply the N-N-N method for calculating the rate constants of $\mathrm{OH}$ reaction with more complex large branched alkanes. The 
measured data in the current work allow us to calculate nine of the sixteen remaining tertiary C-H site-specific rate constants.

For the reaction of 2-methyl-3-ethyl-pentane with $\mathrm{OH}$, the overall rate constant can be decomposed into a combination of $\mathrm{P}, \mathrm{S}$ and $\mathrm{T}$ rates as:

$$
K_{1}=6 P_{1}+6 P_{2}+4 S_{02}+T_{002}+T_{112}
$$

In this equation, all site-specific rates have previously been determined ${ }^{18}$ except $T_{112}$. Since we have obtained expression for $k_{1}$, expression of $T_{112}$ can be derived in Arrhenius form. In the previous sections, we have provided two expressions for $k_{1}$, two-parameter Arrhenius Eq. (1) which is valid over $994-1357 \mathrm{~K}$ and three-parameter Arrhenius Eq. (3) valid over 294 $1357 \mathrm{~K}$. Experimental rate data are not available in the intermediate temperature range, we believe that derived tertiary site-specific rates using Eq. (3) will have larger uncertainty. Therefore, we restricted to the use of only high-temperature rate expressions in this section.

Similar process can be carried out for the other 8 alkanes to obtain equations involving unknown tertiary rates. The overall rate coefficients of the H-abstraction reaction by $\mathrm{OH}$ radical for these alkanes can be decomposed as:

$$
\begin{gathered}
K_{2}=3 P_{1}+9 P_{2}+2 S_{02}+T_{002}+T_{012} \\
K_{3}=6 P_{2}+9 P_{3}+T_{003} \\
K_{4}=3 P_{1}+3 P_{2}+9 P_{3}+2 S_{02}+T_{013} \\
K_{5}=15 P_{2}+2 T_{002}+T_{022} \\
K_{6}=9 P_{1}+6 S_{02}+T_{111} \\
K_{7}=9 P_{2}+9 P_{3}+T_{002}+T_{023} \\
K_{8}=6 P_{1}+9 P_{3}+4 S_{02}+T_{113} \\
K_{9}=3 P_{1}+12 P_{2}+2 S_{02}+2 T_{002}+T_{122}
\end{gathered}
$$

In theory, each one of the Eqs. 12 - 20 may be solved individually to derive the unknown tertiary rate constant. However, it is important to note here that the site-specific $\mathrm{P}, \mathrm{S}$, and $\mathrm{T}$ data in literature ${ }^{18}$ do have some uncertainties and these uncertainties get exasperated when 
the corresponding rate is multiplied by the number of equivalent $\mathrm{C}-\mathrm{H}$ sites. This may lead to relatively large uncertainty in the calculated tertiary site-specific rate. Therefore, rather than treating the literature $\mathrm{P}, \mathrm{S}$, and $\mathrm{T}$ values as fixed, we performed an optimization procedure on the measured rate constants from this work and the rate constants which were used in previous works for the calculation of relevant $\mathrm{P}, \mathrm{S}$, and $\mathrm{T}$ rates.

Sivaramakrishnan et al. ${ }^{15}$ measured rate constants of the reaction of $\mathrm{OH}$ with propane $\left(k_{10}\right)$, iso-butane $\left(k_{11}\right), 2,2,3,3$-tetramethyl-pentane $\left(k_{12}\right), 2,2$-dimethyl-propane $\left(k_{13}\right)$, and 2,3dimethyl-pentane $\left(k_{14}\right)$ and gave the following expressions:

$$
\begin{gathered}
k_{10}=2.42 \times 10^{-17} T^{1.935} \exp (-91 \mathrm{~K} / T) \mathrm{cm}^{3} \text { molecule }{ }^{-1} \mathrm{~s}^{-1}(190-1248 \mathrm{~K}) \\
k_{11}=6.31 \times 10^{-19} T^{2.414} \exp (381 \mathrm{~K} / T) \mathrm{cm}^{3} \text { molecule }{ }^{-1} \mathrm{~s}^{-1}(213-1221 \mathrm{~K}) \\
k_{12}=6.84 \times 10^{-17} T^{1.886} \exp (-365 \mathrm{~K} / \mathrm{T}) \mathrm{cm}^{3} \text { molecule }^{-1} \mathrm{~S}^{-1}(290-1180 \mathrm{~K}) \\
k_{13}=2.80 \times 10^{-16} T^{1.633} \exp (-394 \mathrm{~K} / \mathrm{T}) \mathrm{cm}^{3} \text { molecule } \mathrm{s}^{-1}(287-1259 \mathrm{~K}) \\
k_{14}=2.29 \times 10^{-17} T^{1.196} \exp (365 \mathrm{~K} / T) \mathrm{cm}^{3} \text { molecule } \mathrm{s}^{-1}(220-1292 \mathrm{~K})
\end{gathered}
$$

According to the N-N-N method, $k_{10}$ to $k_{14}$ can be decomposed as:

$$
\begin{gathered}
k_{10}=6 P_{1}+2 S_{00} \\
k_{11}=9 P_{2}+T_{000} \\
P_{3}=0.5\left(\frac{k_{12}}{18}+\frac{k_{13}}{12}\right) \\
k_{14}=2 T_{002}+12 P_{2}
\end{gathered}
$$

Droege et al. ${ }^{10}$ measured the branching ratio of primary and secondary abstraction in propane over $295-854$ K. Sivaramakrishnan et al. ${ }^{23}$ extrapolated this branching ratio to high temperatures $(1300 \mathrm{~K})$ and determined the ratio of $P_{1}$ to $S_{00}\left(k_{15}\right)$, as follows:

$$
\begin{gathered}
k_{15}=0.461 \times T^{0.06} \exp (-469 \mathrm{~K} / T) \mathrm{cm}^{3} \text { molecule }^{-1} \mathrm{~S}^{-1}(295-1300 \mathrm{~K}) \\
k_{15}=\frac{P_{1}}{S_{00}}
\end{gathered}
$$

Similarly, the branching ratios of $\mathrm{OH}+$ iso-butane reaction measured by Tully et al. ${ }^{12}$ was extended to higher temperatures by Sivaramakrishnan et al. ${ }^{23}$. The ratio of $P_{2}$ to $T_{000}\left(k_{16}\right)$ is given here according to the value of $P_{2}$ to $T_{000}$ proposed by Sivaramakrishnan et al. ${ }^{23}$ : 


$$
\begin{gathered}
k_{16}=0.115 \times T^{0.24} \exp (-692 \mathrm{~K} / T) \mathrm{cm}^{3} \text { molecule }^{-1} \mathrm{~S}^{-1}(298-1300 \mathrm{~K}) \\
k_{16}=\frac{P_{2}}{T_{000}}
\end{gathered}
$$

The two ratios, Eqs. (31) and (33), were essential in determining $\mathrm{P}_{1}$ and $\mathrm{P}_{2}$. In our optimization scheme, we also imposed the following expected constraint:

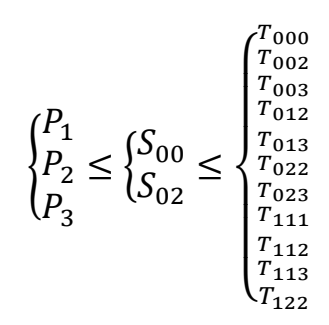

An optimization problem with Eqs. (12) - (33) and inequalities given by (34) was constructed where the objective function is the error between the measured overall rate constants and calculated overall rate constants using the N-N-N method. Genetic algorithm model was utilized in the calculation and derivation of $\mathrm{P}, \mathrm{S}$, and $\mathrm{T}$ values. The calculation result is made up of 9 new site-specific $\mathrm{T}$ values and 7 updated $\mathrm{P}$ and $\mathrm{S}$ values at high temperatures; all of which are listed in Table 3 with relevant references. Utilizing these site-specific rate data, high-temperature rate constants for the reaction of $\mathrm{OH}$ with most of the large branched alkanes may be calculated. It may be noted that some site-specific rates in Table 3 are not updated as these did not appear as variables in the equations which have been used here for optimization.

The Arrhenius expressions for the evaluated tertiary $\mathrm{C}-\mathrm{H}$ sites are:

$$
\begin{aligned}
& T_{003}=1.80 \times 10^{-10} \exp (-2971 \mathrm{~K} / T) \mathrm{cm}^{3} \text { molecule }{ }^{-1} \mathrm{~s}^{-1} \\
& T_{012}=9.36 \times 10^{-11} \exp (-3024 K / T) \mathrm{cm}^{3} \text { molecule }{ }^{-1} \mathrm{~s}^{-1} \\
& T_{013}=4.40 \times 10^{-10} \exp (-4162 \mathrm{~K} / \mathrm{T}) \mathrm{cm}^{3} \text { molecule } \mathrm{e}^{-1} \mathrm{~s}^{-1} \\
& T_{022}=1.47 \times 10^{-10} \exp (-3587 \mathrm{~K} / \mathrm{T}) \mathrm{cm}^{3} \text { molecule }{ }^{-1} \mathrm{~s}^{-1} \\
& T_{023}=6.06 \times 10^{-11} \exp (-3010 \mathrm{~K} / \mathrm{T}) \mathrm{cm}^{3} \text { molecule }{ }^{-1} \mathrm{~s}^{-1} \\
& T_{111}=3.98 \times 10^{-11} \exp (-1617 \mathrm{~K} / \mathrm{T}) \mathrm{cm}^{3} \text { molecule } \mathrm{e}^{-1} \mathrm{~s}^{-1} \\
& T_{112}=9.08 \times 10^{-12} \exp (-3661 \mathrm{~K} / \mathrm{T}) \mathrm{cm}^{3} \text { molecule } \mathrm{e}^{-1} \mathrm{~s}^{-1}
\end{aligned}
$$




$$
\begin{aligned}
& T_{113}=6.74 \times 10^{-9} \exp (-7547 \mathrm{~K} / \mathrm{T}) \mathrm{cm}^{3} \text { molecule } \mathrm{e}^{-1} \mathrm{~s}^{-1} \\
& T_{122}=3.47 \times 10^{-11} \exp (-1802 \mathrm{~K} / \mathrm{T}) \mathrm{cm}^{3} \text { molecule }{ }^{-1} \mathrm{~s}^{-1}
\end{aligned}
$$

Table 3.

Summary of site-specific rate constants for $\mathrm{H}$-abstraction by $\mathrm{OH}$, according to the expression $A T^{b} \exp ^{(-E / T)} \mathrm{cm}^{3}$ molecule $\mathrm{s}^{-1}$. The rates which were available previously in literature but have been updated in the current work during the optimization process are labelled as "This work

\begin{tabular}{|c|c|c|c|c|c|}
\hline $\begin{array}{l}\text { Site- } \\
\text { specific } \\
\text { rate } \\
\text { constant } \\
\end{array}$ & A & $\mathrm{b}$ & $\mathrm{E}$ & T range $[\mathrm{K}]$ & Ref. \\
\hline $\mathrm{P}_{0}$ & $4.47 \times 10^{-19}$ & 2.22 & 373 & $298-1300$ & Sivaramakrishnan and Michael ${ }^{23}$ \\
\hline $\mathrm{P}_{1}$ & $7.56 \times 10^{-18}$ & 1.81 & 437 & $298-1300$ & Sivaramakrishnan and Michael ${ }^{23}$ \\
\hline $\mathrm{P}_{1}$ & $(1.62 \pm 0.11) \times 10^{-11}$ & 0 & $2610 \pm 82$ & $950-1300$ & This work (updated) \\
\hline $\mathrm{P}_{2}$ & $9.27 \times 10^{-19}$ & 2.08 & 189 & $298-1300$ & Sivaramakrishnan and Michael ${ }^{23}$ \\
\hline $\mathrm{P}_{2}$ & $(1.58 \pm 0.04) \times 10^{-11}$ & 0 & $2517 \pm 30$ & $950-1300$ & This work (updated) \\
\hline $\mathrm{P}_{3}$ & $9.09 \times 10^{-18}$ & 1.76 & 374 & $298-1300$ & Sivaramakrishnan and Michael ${ }^{23}$ \\
\hline $\mathrm{P}_{3}$ & $(1.19 \pm 0.08) \times 10^{-11}$ & 0 & $2400 \pm 62$ & $950-1300$ & This work (updated) \\
\hline $\mathrm{S}_{00}$ & $1.64 \times 10^{-17}$ & 1.75 & -32 & $298-1300$ & Sivaramakrishnan and Michael ${ }^{23}$ \\
\hline $\mathrm{S}_{00}$ & $(2.00 \pm 0.05) \times 10^{-11}$ & 0 & $2046 \pm 26$ & $950-1300$ & This work (updated) \\
\hline $\mathrm{S}_{10}$ & $5.86 \times 10^{-15}$ & 0.93 & 254 & $298-1300$ & Sivaramakrishnan and Michael ${ }^{23}$ \\
\hline $\mathrm{S}_{11}$ & $4.75 \times 10^{-18}$ & 1.811 & -511 & $298-1300$ & Sivaramakrishnan and Michael ${ }^{23}$ \\
\hline $\mathrm{S}_{11^{\prime}}$ & $4.66 \times 10^{-13}$ & 0.32 & 426 & $298-1300$ & Sivaramakrishnan and Michael ${ }^{23}$ \\
\hline $\mathrm{S}_{20}$ & $8.49 \times 10^{-17}$ & 1.52 & -73.4 & $250-1450$ & Badra and Farooq ${ }^{18}$ \\
\hline $\mathrm{S}_{20}$ & $(1.57 \pm 0.11) \times 10^{-11}$ & 0 & $1885 \pm 70$ & $950-1300$ & This work (updated) \\
\hline $\mathrm{S}_{21}$ & $4.60 \times 10^{-15}$ & 0.86 & -142 & $296-1440$ & Badra and Farooq ${ }^{18}$ \\
\hline $\mathrm{S}_{22}$ & $2.88 \times 10^{-13}$ & 0.41 & 291.5 & $272-1311$ & Badra and Farooq ${ }^{18}$ \\
\hline $\mathrm{S}_{30}$ & $3.35 \times 10^{-18}$ & 1.966 & -323 & $250-1366$ & Badra and Farooq ${ }^{18}$ \\
\hline $\mathrm{S}_{31}$ & $1.60 \times 10^{-18}$ & 2 & -500 & $250-1351$ & Badra and Farooq ${ }^{18}$ \\
\hline $\mathrm{S}_{32}$ & $9.65 \times 10^{-17}$ & 1.45 & -180 & $297-1367$ & Badra and Farooq ${ }^{18}$ \\
\hline $\mathrm{S}_{33}$ & $2.83 \times 10^{-19}$ & 2.25 & -501.3 & $250-1365$ & Badra and Farooq ${ }^{18}$ \\
\hline $\mathrm{T}_{000}$ & $8.04 \times 10^{-18}$ & 1.84 & -503 & $298-1300$ & Sivaramakrishnan and Michael ${ }^{23}$ \\
\hline $\mathrm{T}_{000}$ & $(1.90 \pm 0.04) \times 10^{-11}$ & 0 & $1568 \pm 22$ & $950-1300$ & This work (updated) \\
\hline $\mathrm{T}_{100}$ & $4.00 \times 10^{-15}$ & 1 & -5 & $297-1375$ & Badra and Farooq ${ }^{18}$ \\
\hline $\mathrm{T}_{101}$ & $1.05 \times 10^{-16}$ & 1.38 & -577 & $297-1362$ & Badra and Farooq ${ }^{18}$ \\
\hline $\mathrm{T}_{200}$ & $7.84 \times 10^{-14}$ & 0.58 & -35 & $298-1300$ & Sivaramakrishnan and Michael ${ }^{23}$ \\
\hline $\mathrm{T}_{200}$ & $(1.07 \pm 0.12) \times 10^{-11}$ & 0 & $984 \pm 124$ & $950-1300$ & This work (updated) \\
\hline
\end{tabular}
(updated)". 


\begin{tabular}{llllll}
$\mathrm{T}_{003}$ & $(1.80 \pm 0.11) \times 10^{-10}$ & 0 & $2971 \pm 64$ & $950-1300$ & This work \\
$\mathrm{T}_{012}$ & $(9.36 \pm 1.42) \times 10^{-11}$ & 0 & $3024 \pm 148$ & $950-1300$ & This work \\
$\mathrm{T}_{013}$ & $(4.40 \pm 0.22) \times 10^{-10}$ & 0 & $4162 \pm 53$ & $950-1300$ & This work \\
$\mathrm{T}_{022}$ & $(1.47 \pm 0.21) \times 10^{-10}$ & 0 & $3587 \pm 147$ & $950-1300$ & This work \\
$\mathrm{T}_{023}$ & $(6.06 \pm 0.67) \times 10^{-11}$ & 0 & $3010 \pm 140$ & $950-1300$ & This work \\
$\mathrm{T}_{122}$ & $(3.47 \pm 0.78) \times 10^{-11}$ & 0 & $1802 \pm 217$ & $950-1300$ & This work \\
$\mathrm{T}_{113}$ & $(6.74 \pm 0.34) \times 10^{-9}$ & 0 & $7547 \pm 57$ & $950-1300$ & This work \\
$\mathrm{T}_{112}$ & $(9.08 \pm 1.48) \times 10^{-11}$ & 0 & $3661 \pm 431$ & $950-1300$ & This work \\
$\mathrm{T}_{111}$ & $(3.98 \pm 0.85) \times 10^{-11}$ & 0 & $1617 \pm 199$ & $950-1300$ & This work \\
\hline
\end{tabular}

Figure 9 plots all measured site-specific rate constants over 950 - $1300 \mathrm{~K}$, including four primary, eleven secondary, and thirteen tertiary rates. Generally, tertiary rate constants are higher than secondary, and secondary rate constants are higher than primary ones. However, some tertiary rates have values similar to secondary rates. The differences among primary site-specific rates are less than those of secondary and tertiary rates. Among the primary rates, $\mathrm{P}_{0}$ has the largest rate constant. Within the secondary rates, $\mathrm{S}_{30}$ and $\mathrm{S}_{10}$ have largest values of site-specific rate constants. Finally, $\mathrm{T}_{003}, \mathrm{~T}_{013}, \mathrm{~T}_{111}$ and $\mathrm{T}_{113}$ have values larger than other tertiary rates. Overall rate constant calculated from the N-N-N data obtained in this work are plotted in Figure 3 and 4, and agree very well with the experimental data. 

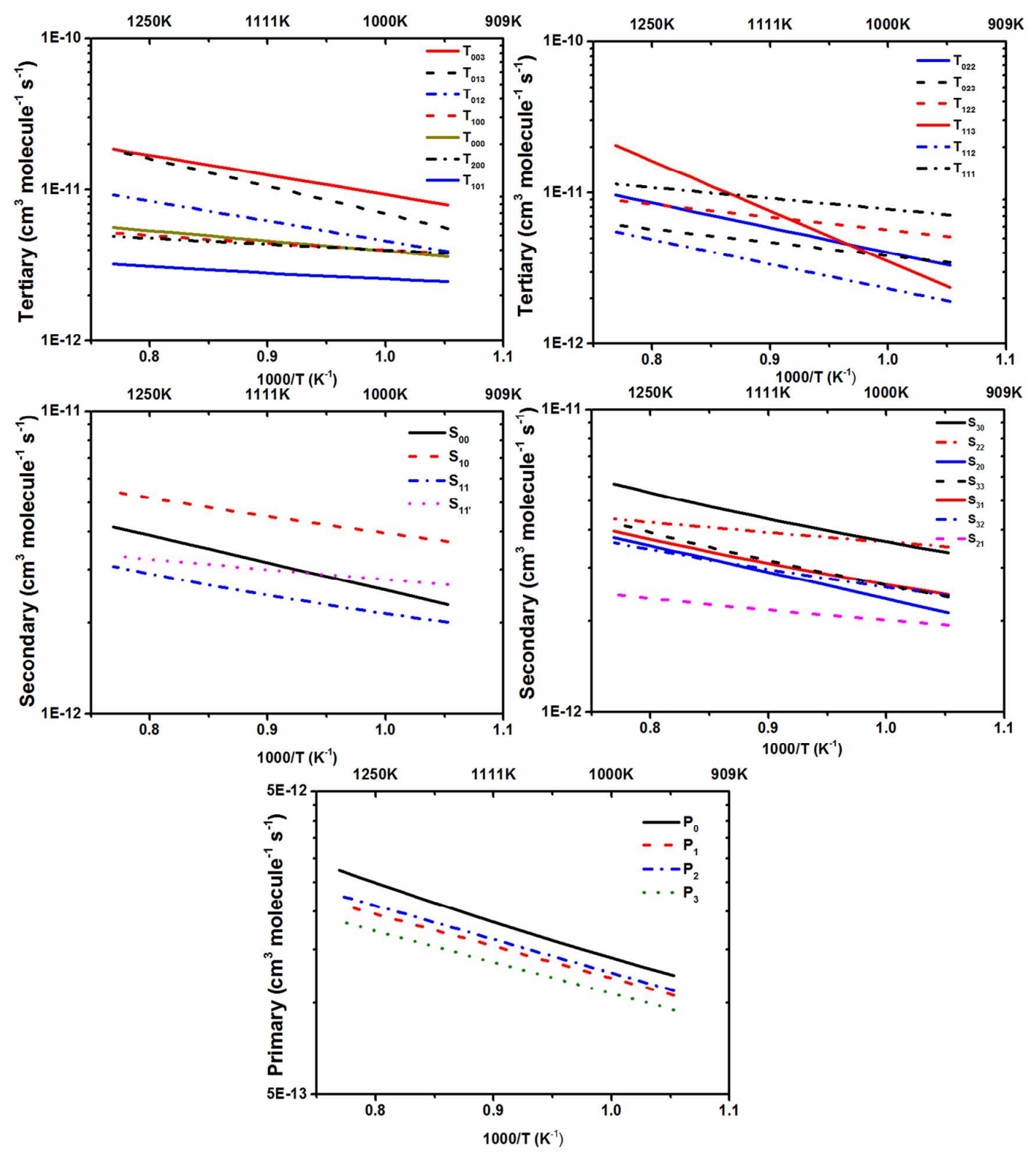

Fig. 9. Arrhenius plot of site-specific rate constants over 950-1300 K. 


\section{Conclusions}

Reaction rate constants for large branched alkanes with $\mathrm{OH}$ were measured in a shock tube at high temperatures and in a flow reactor at room temperature. Three-parameter Arrhenius expressions were developed over a wide temperature interval (about 300-1300 K) for the reaction of $\mathrm{OH}$ with nine branched alkanes. The structure-activity-relationship (SAR) estimation values agree reasonably with experimental data for most of the alkanes, while some obvious discrepancy was observed for 2,2,3-trimethyl-butane, 2,2,3,4-tetramethylpentane, and 2,2-dimethyl-3-ethyl-pentane.

Nine tertiary $\mathrm{C}-\mathrm{H}$ site-specific rate constants were derived and several primary and secondary $\mathrm{H}$-abstraction values were updated for alkanes in the high-temperature region. This work extends the validity of the next-nearest-neighbor $(\mathrm{N}-\mathrm{N}-\mathrm{N})$ method to more complicated branched alkanes.

\section{Supplementary Material:}

Raw experimental data, calculation of branch ratios, and plots of wide-temperature-range rate constant are provided in the Supplementary Material.

\section{Acknowledgements}

We would like to acknowledge the funding support from Saudi Aramco under the FUELCOM program and by King Abdullah University of Science and Technology (KAUST). Financial support by the French ANR agency under contract No. ANR-11-LabEx-0005-01 CaPPA (Chemical and Physical Properties of the Atmosphere) is acknowledged. 


\section{References}

1. J.T.Farrell; N.P. Cernansky; F.L. Dryer and C.K. Law, D. G. F., C.A.Hergart, R.M.McDavid ; A.K. Patel; C.J. Mueller; H.Pitsch. Development of an Experimental Database and Kinetic Models for Surrogate Diesel Fuels. SAE Technical Paper 2007, No. 2007-01-0201.

2. Vasu, S. S.; Davidson, D. F.; Hong, Z.; Vasudevan, V.; Hanson, R. K. N-Dodecane Oxidation at High-Pressures: Measurements of Ignition Delay Times and Oh Concentration Time-Histories. Proceedings of the Combustion Institute 2009, 32, 173-180.

3. Zador, J.; Jasper, A. W.; Miller, J. A. The Reaction between Propene and Hydroxyl. Phys Chem Chem Phys 2009, 11, 11040-53.

4. Bott, J. F.; Cohen, N. A Shock Tube Study of the Reactions of the Hydroxyl Radical with Several Combustion Species. International Journal of Chemical Kinetics 1991, 23 (12), $1075-1094$.

5. Droege, A. T.; Tully, F. P. Hydrogen-Atom Abstraction from Alkanes by Hydroxyl Radical. 6. Cyclopentane and Cyclohexane. J. Phys. Chem. 1987, 91, 1222-1225.

6. Tully, F. P.; Koszykowski, M. L.; Binkley, J. S. Hydrogen-Atom Abstraction from Alkanes by Oh. I. Neopentane and Neooctane. Twentieth Symposium (International) on Combustion 1985, 20, 715-721.

7. Tully, F. P.; Droege, A. T.; Koszykowski, M. L.; Melius, C. F. Hydrogen-Atom Abstraction from Alkanes by Hydroxyl. 2. Ethane. J. Phys. Chem. 1986, 90, 691-698.

8. Atkinson, R. Gas-Phase Tropospheric Chemistry of Volatile Organic Compounds .1. Alkanes and Alkenes. Journal of Physical and Chemical Reference Data 1997, 26, 215-290.

9. Atkinson, R. Gas-Phase Tropospheric Chemistry of Organic-Compounds - a Review. Atmos Environ a-Gen 1990, 24, 1-41. 
10. Droege, A. T.; Tully, F. P. Hydrogen-Atom Abstraction from Alkanes by Oh .3. Propane. Journal of Physical Chemistry 1986, 90, 1949-1954.

11. Dunlop, J. R.; Tully, F. P. A Kinetic Study of Hydroxyl Radical Reactions with Methane and Perdeuterated Methane. The Journal of Physical Chemistry 1993, 97 (43), 11148-11150.

12. TUlly, F.; GOLDSMITH,J.; DROEGE, A.T. Hydrogen - Atom Abstraction from Alkanes by Oh. Part 4. Isobutane. ChemInform 1987 18(10).

13. Bott, J. F.; Cohen, N. A Shock Tube Study of the Reactions of the Hydroxyl Radical with Several Combustion Species. International Journal of Chemical Kinetics 1991, 23, 1075-1094.

14. Cohen, N. The Use of Transition-State Theory to Extrapolate Rate Coefficients for Reactions of Oh with Alkanes. International Journal of Chemical Kinetics 1982, 14, 13391362.

15. Sivaramakrishnan, R.; Michael*, J. V. Rate Constants for Oh with Selected Large Alkanes: Shock-Tube Measurements and an Improved Group Scheme. J. Phys. Chem. A 2009, 113, 5047-5060.

16. Pang, G. A.; Hanson, R. K.; Golden, D. M.; Bowman, C. T. High-Temperature Measurements of the Rate Constants for Reactions of Oh with A series of Large Normal Alkanes:N-Pentane,N-Heptane, Andn-Nonane. Zeitschrift für Physikalische Chemie 2011, $225,1157-1178$.

17. Badra, J.; Elwardany, A.; Farooq, A. Shock Tube Measurements of the Rate Constants for Seven Large Alkanes+Oh. Proceedings of the Combustion Institute 2015, 35, 189-196.

18. Badra, J.; Farooq, A. Site-Specific Reaction Rate Constant Measurements for Various Secondary and Tertiary H-Abstraction by Oh Radicals. Combustion and Flame 2015, 162, 2034-2044. 
19. Cohen, N. Are Reaction-Rate Coefficients Additive - Revised Transition-State Theory Calculations for Oh + Alkane Reactions. International Journal of Chemical Kinetics 1991, $23,397-417$.

20. Kwok, E. S. C.; Atkinson, R. Estimation of Hydroxyl Radical Reaction-Rate Constants for Gas-Phase Organic-Compounds Using a Structure-Reactivity Relationship - an Update. Atmos Environ 1995, 29, 1685-1695.

21. Atkinson, R. Kinetics and Mechanisms of the Gas-Phase Reactions of the Hydroxyl Radical with Organic Compounds under Atmospheric Conditions. Chem. Rev. 1986, 86, 69201.

22. Cohen, N. Are Reaction Rate Coefficients Additive Revised Transition State Theory Calculations for Oh + Alkane Reactions. International Journal of Chemical Kinetics 1991, $23,397-417$.

23. Sivaramakrishnan, R.; Michael, J. V. Rate Constants for Oh with Selected Large Alkanes: Shock-Tube Measurements and an Improved Group Scheme. J Phys Chem A 2009, $113,5047-60$.

24. Wilson, E. W.; Jr., W. A. H. H. R. K.; Bill Evans , I.; Scott, a. N. W. Measurement and Estimation of Rate Constants for the Reactions of Hydroxyl Radical with Several Alkanes and Cycloalkanes. J. Phys. Chem. A 2006, 110, 3593-3604.

25. Roger Atkinson; William P. L. Carter; Sara M. Aschmann; Arthur M. Winer; Jr., J. N. P. Kinetics of the Reaction of Oh Radicals with a Series of Branched Alkanes at 297 K 2 K. International Journal of Chemical Kinetics 1984, 16, 469-481.

26. Karen R. Darnall; Arthur M. Winer; Alan C. Lloyd; Jr., J. N. P. Relative Rate Constants for the Reaction of Oh Radicals with Selected C6 and C7 Alkanes and Alkenes at $305 \pm 2$ K. Chemical Physics Letters 1976, 44, 415-418. 
27. Greiner, N. R. Hydroxyl Radical Kinetics by Kinetic Spectroscopy. Vi. Reactions with Alkanes in the Range $300-500^{\circ} \mathrm{K}$. The Journal of Chemical Physics 1970, 53, 1070.

28. Aschmann, S. M.; *†, J. A.; *†t, a. R. A. Products and Mechanism of the Reaction of Oh Radicals with 2,3,4-Trimethylpentane in the Presence of No. Environ. Sci. Technol. 2004, $38,5038-5045$.

29. Edmond W. Wilson, J., * Wesley A. Hamilton ,; Hillary R. Kennington ; Bill Evans , I.; Scott, a. N. W. Measurement and Estimation of Rate Constants for the Reactions of Hydroxyl Radical with Several Alkanes and Cycloalkanes. J. Phys. Chem. A 2006, 110, $3593-3604$.

30. Badra, J.; Elwardany, A. E.; Farooq, A. Reaction Rate Constants of H-Abstraction by Oh from Large Ketones: Measurements and Site-Specific Rate Rules. Phys Chem Chem Phys 2014, 16, 12183-93.

31. Badra, J.; Elwardany, A. E.; Khaled, F.; Vasu, S. S.; Farooq, A. A Shock Tube and Laser Absorption Study of Ignition Delay Times and Oh Reaction Rates of Ketones: 2Butanone and 3-Buten-2-One. Combustion and Flame 2014, 161, 725-734.

32. Vasudevan, V.; Davidson, D. F.; Hanson, R. K. High-Temperature Measurements of the Reactions of Oh with Toluene and Acetone. Journal of Physical Chemistry A 2005, 109, 3352-3359.

33. Zekai Hong*; Subith S. Vasu; Davidson, D. F.; Hanson, a. R. K. Experimental Study of the Rate of $\mathrm{Oh}+\mathrm{Ho} 2 \mathrm{~F} \mathrm{H} 2 \mathrm{o}+\mathrm{O} 2$ at High Temperatures Using the Reverse Reaction. $J$. Phys. Chem. A 2010, 114, 5520-5525.

34. Pang, G. A.; Hanson, R. K.; Golden, D. M.; Bowman, C. T. Rate Constant Measurements for the Overall Reaction of Oh + 1-Butanol --> Products from 900 to $1200 \mathrm{~K} . J$ Phys Chem A 2012, 116, 2475-83. 
35. D.F. Davidson †; A.Y. Chang; M.D. Di Rosa; Hanson, R. K. A Cw Laser Absorption Diagnostic for Methyl Radicals. Journal of Quantitative Spectroscopy and Radiative Transfer 1993, 49, 559-571.

36. Klingbeil, A. E.; Jeffries, J. B.; Hanson, R. K. Temperature- and Pressure-Dependent Absorption Cross Sections of Gaseous Hydrocarbons at 3.39 Mu M. Measurement Science and Technology 2006, 17, 1950-1957.

37. Sarathy, S. M.; Westbrook, C. K.; Mehl, M.; Pitz, W. J.; Togbe, C.; Dagaut, P.; Wang, H.; Oehlschlaeger, M. A.; Niemann, U.; Seshadri, K.; et al. Comprehensive Chemical Kinetic Modeling of the Oxidation of 2-Methylalkanes from C7 to C20. Combustion and Flame 2011, 158 (12), 2338-2357.

38. Parker, A.; Jain, C.; Schoemaecker, C.; Fittschen, C. Kinetics of the Reaction of Oh Radicals with $\mathrm{Ch}_{3}$ oh and $\mathrm{Cd}_{3}$ od Studied by Laser Photolysis Coupled to High Repetition Rate Laser Induced Fluorescence. Reaction Kinetics and Catalysis Letters 2009, 96, 291-297.

39. Bossolasco, A.; Faragó, E. P.; Schoemaecker, C.; Fittschen, C. Rate Constant of the Reaction between $\mathrm{Ch}_{3} \mathrm{O}_{2}$ and Oh Radicals. Chemical Physics Letters 2014, 593, 7-13.

40. Faragó, E. P.; Schoemaecker, C.; Viskolcz, B.; Fittschen, C. Experimental Determination of the Rate Constant of the Reaction between $\mathrm{C}_{2} \mathrm{~h}_{5} \mathrm{O}_{2}$ and Oh Radicals. Chemical Physics Letters 2015, 619, 196-200.

41. Thiebaud, J.; Aluculesei, A.; Fittschen, C. Formation of $\mathrm{Ho}_{2}$ Radicals from the Photodissociation of $\mathrm{H}_{2} \mathrm{O}_{2}$ at $248 \mathrm{Nm}$. The Journal of Chemical Physics 2007, 126, 186101.

42. Wang, S.; Li, S.; Davidson, D. F.; Hanson, R. K. Shock Tube Measurement of the High-Temperature Rate Constant for Oh + Ch3 --> Products. J Phys Chem A 2015, 119, 8799-805. 


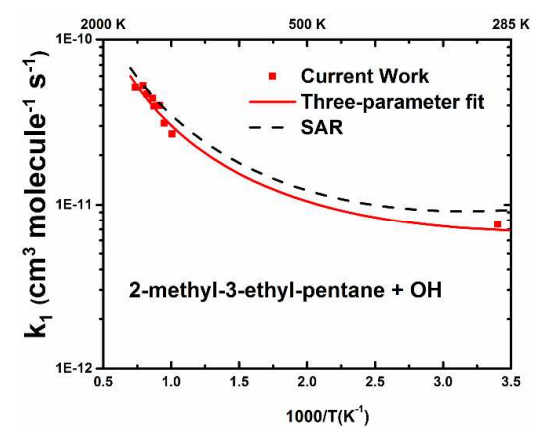

TOC Graphic 